\title{
Desflurane anaesthesia in a patient with multiple sclerosis in total hip replacement
}

Levent Sahin'1, Halil F. Korkmaz², Mehrican Sahin², Tayfun Aydin¹, Serdar Toker ${ }^{3}$, Erim Gulcan ${ }^{4}$

1Department of Anesthesiology, Faculty of Medicine, Dumlupinar University, Kutahya,
Turkey
2Department of Anesthesiology, Government Hospital, Kutahya, Turkey
${ }^{3}$ Department of Orthopedics, Faculty of Medicine, Dumlupinar University, Kutahya, Turkey
${ }^{4}$ Department of Internal Medicine, Faculty of Medicine, Dumlupinar University, Kutahya,
Turkey

Submitted: 12 September 2009

Accepted: 6 December 2009

Arch Med Sci 2010; 6, 6: 984-986

DOI: 10.5114/aoms.2010.19314

Copyright (c) 2010 Termedia \& Banach

\author{
Corresponding author: \\ Erim Gulcan, MD \\ Department of Internal \\ Medicine \\ Faculty of Medicine \\ Dumlupinar University \\ Tavsanlı Yolu 10.km 43100 \\ Kutahya, Turkey \\ Phone: +902742652031 \\ Fax: +90 2742652277 \\ E-mail: \\ drerimgulcan@gmail.com
}

\begin{abstract}
Multiple sclerosis (MS) is a progressive demyelinating disease presenting with a relapsing-remitting course and affects large areas of the brain and the spinal cord. Surgical stress often induces exacerbation of MS symptoms. It is mandatory to prepare the MS patient very carefully for the surgery and anaesthesia with an effective premedication and an effective postoperative analgesia following a safe and minimal-risk anaesthesia management. In recent reports, results of general and regional anaesthesia in MS patients have been discussed. To our knowledge this is the first case report of the use of desflurane anaesthesia in a patient with MS. In conclusion, desflurane anaesthesia is a safe and useful method for MS patients.
\end{abstract}

Key words: anaesthesia, desflurane, multiple sclerosis

\section{Introduction}

Multiple sclerosis (MS) is a progressive demyelinating disease presenting with a relapsing-remitting course [1]. High doses of corticosteroids used in the treatment of this disease may cause avascular necrosis in the femoral head. Surgical stress often induces exacerbation of MS symptoms. Therefore, effective anaesthesia is required for anaesthetic management in cases of MS [2,3]. We aimed to report the desflurane anaesthesia that we performed in an MS patient operated on for total hip replacement. To our knowledge this is the first case of desflurane anaesthesia in an MS patient in the literature.

\section{Case report}

A 31-year-old male patient with MS for 11 years was planned to have a total hip prosthesis replacement for femoral head avascular necrosis due to long-term steroid intake. He had not experienced any attacks for the last 2 years. He was operated on for avascular necrosis of the other hip under spinal anaesthesia two years ago without any problems according to the patient history. In his preoperative examination, motor strength was $-5 / 5$ on the left side, deep tendon reflexes were hyperactive, plantar skin reflexes were bilaterally nonchalant, and he had neurogenic bladder. Other physical examination and laboratory findings were normal. $5 \mathrm{mg}$ 
of midazolam was administered intramuscularly before taking the patient into the patient room. Routine monitoring was performed in the operating room. $15 \mathrm{mg}$ of etomidate, $1 \mu \mathrm{g} / \mathrm{kg}$ of remifentanil, and $7 \mathrm{mg}$ of vecuronium bromide were used in anaesthesia induction and the patient was connected to a mechanical ventilator following tracheal intubation. Continuation of anaesthesia was performed with $0.2 \mu \mathrm{g} / \mathrm{kg} / \mathrm{m}$ remifentanil infusion and 5-6\% concentration of desflurane in $\mathrm{N}_{2} \mathrm{O}$ and $\mathrm{O}_{2}$ mixture. When the surgeon began skin closure remifentanil infusion was stopped and $70 \mathrm{mg}$ of dolantin was administered intramuscularly. Haemodynamic findings were stable throughout the process and the patient recovered and was extubated at the end of surgery normally. The postoperative analgesia regimen was ordered in a conventional manner with non-steroid antiinflammatory and opioid analgesic drugs. He did not have any symptoms or an attack due to MS during hospitalization.

\section{Discussion}

To our knowledge this is the first case report of the use of desflurane anaesthesia in a patient with MS. Also, this is the first case report in which remifentanil was used except for one case in which remifentanil was used for postoperative intravenous patient-controlled analgesia [1].

It was reported that MS attacks might not only occur spontaneously but also in stressful conditions, infection [2], pregnancy [3], following a surgical procedure and under anaesthesia [4]. For these reasons, it is mandatory to prepare the patient very carefully for the surgery and anaesthesia with an effective premedication and an effective postoperative analgesia following a safe and minimal-risk anaesthesia management [5]. In recent reports, results of general and regional anaesthesia in MS patients have been discussed. Unfortunately there is not a controlled clinical trial comparing general and regional anaesthesia procedures in MS patients. There are a few retrospective studies and case reports in the literature. Most of the case reports are obstetric. It is possible to find reports about the advantages and disadvantages of neuraxial blocks in the literature. According to many authors, using regional anaesthesia for MS patients is still a matter of confusion $[4,6,7]$. However, it is not yet respected as a contraindication. Kyatta et al. [8] reported that hypotension resistant to hydration and vasopressors occurred in all 4 MS patients who received regional anaesthesia in a total of 56 MS patients in 10-year follow-up. They did not comment on times of neural blockade, and speculated that the local anaesthetic may have damaged the spinal cord or much more may have been taken because of demyelization. Under central neural block, MS attacks may be correlated with local anaesthetic. Is it possible that there is greater uptake of local anaesthetics into the spinal cord following subarachnoid, epidural or paravertebral blocks in patients with MS? This effect has a much greater risk in spinal anaesthesia than in epidural anaesthesia because an intrathecal local anaesthetic may directly bathe the nerve roots at higher concentrations [9]. In that study, LA in the white matter of the spinal cord was found 3-4 times more in the spinal anaesthesia than epidural. Local anaesthetic toxicity in demyelinating spinal nerves may increase complications such as acute spinal syndrome, paralysis and bladder dysfunction. Brendan et al. [10] reported a prolonged central block occurring with flaccid paralysis in both legs, hypotension, and urinary retention following paravertebral combined with general anaesthesia in a patient with undiagnosed MS. They speculated that it was due to abnormal uptake of the LA into demyelinated nerves. Additionally, when regional block combines with general anaesthesia, characteristics of the block and neurological complications are not recognized. Borgeat et al. [11] reported severe plexopathy following brachial plexus block in an MS patient. That case showed that neurological complications can be seen following not only central neural block but also peripheral block. Bamford et al. [4] concluded that spinal anaesthesia should be the final choice in MS patients. Bader AM et al. [5] reported a 5-year retrospective prospective combined study about MS which applied epidural LA for vaginal delivery, and they did not find any difference in safety between epidural and general anaesthesia when bupivacaine concentration was equal or under $0.25 \%$. Higher doses were reported to be responsible for an increase in relapse rates.

A common problem in regional block is unpredictable abnormal uptake of LA due to demyelization of the spinal cord and nerves, and complications are associated with that according to its severity. Such problems are hypotension, prolonged neural blockade, flaccid paralysis, urinary retention, and acute spinal syndrome. Additionally, the volume and concentration of LA applied may be important. In this case, we tended to use general anaesthesia because of the controversy about regional anaesthesia in MS patients. It was reported that some drugs, such as TPS ve Sch, have the potential to cause an exacerbation. In addition, in all general procedures body temperature might be increased [12]. However, drugs such as sevoflurane and propofol have been used before without any problems [13-15].

There are no reports on desflurane anaesthesia in MS patients in the literature. Desflurane is an inhalation anaesthetic with a rapid onset and 
recovery, and it was observed that protective airway reflexes return more quickly than with sevoflurane [16]. Moreover, it was realized that sevoflurane has more toxic metabolites and has more damaging effects on the kidneys [17]. Comparing the inhalant agents, we think that the most appropriate agent is desflurane.

We used remifentanil as an induction and perioperative analgesic. Remifentanil, also a strong analgesic, is a suitable agent for stable anaesthesia with a rapid onset and a short half-life with plasma esterases [18]. Because of the short duration of action, a combination of propofol and remifentanil seems to be an alternative method, but hypotension and bradycardia may occur. In lower doses, it is possible that an MS attack may occur because of lack of an effective anaesthesia.

In conclusion, we believe that general anaesthesia has less risk of complications than regional methods in MS patients and desflurane is a safe agent to use in these patients.

\section{References}

1. López-Millán JM, Blanco L, Alcañiz JB, De las Mulas M. Intravenous patient-controlled analgesia with remifentanil for labor and childbirth in a woman with multiple sclerosis. Rev Esp Anestesiol Reanim 2007; 54: 200-2.

2. McDonald WI, Silberberg DH. Multiple Sclerosis. London, Butterworth 1968, 216-8.

3. Nelson LM, Franklin GM, Jones MC. Risk of multiple sclerosis exacerbation during pregnancy and breastfeeding. JAMA 1988; 259: 3441-3.

4. Bamford C, Sibley W, Laguna J. Anesthesia in multiple sclerosis. Can J Neurol Sci 1978; 5: 41-4.

5. Bader AM, Hunt CO, Datta S, Naulty JS, Ostheimer GW. Anesthesia for the obstetric patient with multiple sclerosis. J Clin Anesth 1988; 1: 21-4.

6. Vadalouca A, Moka E, Sykiotis C. Combined spinal-epidural technique for total hysterectomy in a patient with advanced, progressive multiple sclerosis. Reg Anesth Pain Med 2002; 7: 540-1.

7. Warren TM, Datta S, Ostheimer GW. Lumbar epidural anesthesia in a patient with multiple sclerosis. Anesth Analg 1982; 61: 1022-3.

8. Kytta J, Rosenberg PH. Anaesthesia for patients with multiple sclerosis. Ann Chir Gynaecol 1984; 73: 299-303.

9. Bromage PR.Mechanism of action of extradural analgesia. Br J Anaesth 1975; 47 (Suppl.): 199-211.

10. Finucane BT, Terblanche OC. Prolonged duration of anesthesia in a patient with multiple sclerosis following paravertebral block. Can J Anaesth 2005; 52: 493-7.

11. Borgeat A, Aguirre J, Neudörfer C, Jutzi H. Severe brachial plexopathy after an Ultrasound-guided single-injection nerve block for total shoulder arthroplasty in a patient with multiple sclerosis: what is the likely cause of this complication? Anesthesiology 2008; 109: 750-1; author reply 753.

12. Jones R, Healy T. Anaesthesia and demyelinating disease. Anaesthesia 1980; 35: 879-84.

13. Matsuura T, Okawa I, Matsukawa T, Furuya A. Anesthetic management of a patient with multiple sclerosis using propofol. Masui 1998; 47: 1237-9.
14. Yamashita K, Yokoyama T, Tokai H, Imazu Y, Lee M, Manabe M. Anesthetic management for a patient with multiple sclerosis at exacerbation stage under general anesthesia. Masui 2003; 52: 521-3.

15. Kohno K, Uchida H, Yamamoto N, Kosaka Y. Sevoflurane anesthesia in a patient with multiple sclerosis. Masui 1994; 43: 1229-32.

16. McKay RE, Large MJ, Balea MC, McKay WR. Airway reflexes return more rapidly after desflurane anesthesia than after sevoflurane anesthesia. Anesth Analg 2005; 100: 697-700.

17. Eger El 2nd, Koblin DD, Bowland T, et al. Nephrotoxicity of sevoflurane versus desflurane anesthesia in volunteers. Anesth Analg 1998; 86: 445-6.

18. Glass PS. Remifentanil: a new opioid. J Clin Anesth 1995; 7: 558-63. 